\title{
Equity and diversity in academic medicine: a perspective from the $\mathrm{JCl}$ editors
}

\author{
Linda M.S. Resar, ${ }^{1,2,3,4}$ Elizabeth M. Jaffee, ${ }^{4}$ Mary Armanios, ${ }^{2,4,5,6}$ Sarah Jackson, ${ }^{7}$ Nilofer S. Azad, ${ }^{2,4}$ Maureen R. Horton, ${ }^{8}$ \\ Mariana J. Kaplan, ${ }^{9}$ Marikki Laiho, ${ }^{4,10,11}$ Marcela V. Maus, ${ }^{12,13}$ Charlotte J. Sumner, ${ }^{14,15}$ Sarah J. Wheelan, ${ }^{2,4,16,17}$ and Marsha Wills-Karp ${ }^{18}$
}

'Division of Hematology, Department of Medicine, ${ }^{2}$ Department of Oncology, and ${ }^{3}$ Department of Pathology, Johns Hopkins University School of Medicine, Baltimore, Maryland, USA. ${ }^{4}$ Sidney Kimmel Comprehensive Cancer Center at Johns Hopkins, Baltimore, Maryland, USA. ${ }^{5}$ Telomere Center and ${ }^{6}$ Department of Cenetic Medicine, Johns Hopkins University School of Medicine, Baltimore, Maryland, USA. ${ }^{7}$ Journal of Clinical Investigation, Ann Arbor, Michigan, USA. ${ }^{8}$ Department of Medicine, Johns Hopkins University School of Medicine, Baltimore, Maryland, USA. ${ }^{9}$ Systemic Autoimmunity Branch, Intramural Research Program (IRP), National Institute of Arthritis and Musculoskeletal and Skin Diseases (NIAMS), NIH, Bethesda, Maryland, USA. ${ }^{10}$ Department of Radiation Oncology and Molecular Radiation Sciences, Johns Hopkins University School of Medicine, Baltimore, Maryland, USA. "Division of Pharmaceutical Biosciences, Faculty of Pharmacy and Institute of Biotechnology, University of Helsinki, Helsinki, Finland. ${ }^{12}$ Cellular Immunotherapy Program, Cancer Center, and ${ }^{13}$ Department of Medicine, Massachusetts General Hospital and Harvard Medical School, Boston, Massachusetts, USA. ${ }^{14}$ Department of Neurology and ${ }^{15}$ Department of Neuroscience, Johns Hopkins University School of Medicine, Baltimore, Maryland, USA. ${ }^{16}$ Department of Biostatistics, Bloomberg School of Public Health, Johns Hopkins University, Baltimore, Maryland, USA. ${ }^{17}$ Department of Molecular Biology and Genetics, Johns Hopkins University School of Medicine, Baltimore, Maryland, USA. ${ }^{18}$ Department of Environmental Health and Engineering, Bloomberg School of Public Health, Johns Hopkins University, Baltimore, Maryland, USA.

\section{\#MeToo in academia}

The \#MeToo movement has taken on sexual harassment in the workplace and served to inform the world that these unacceptable and illegal acts have become commonplace, including in academic settings (1). Through this platform, women are empowering each other to fight back against egregious behaviors that have infiltrated the workplace for decades. However, there are more subtle ways in which women can be demeaned in the workplace (1). Historically, women have been excluded from leadership positions in academic medicine. Importantly, while it is clear that gender-based and racial disparities are pervasive, concrete solutions to rectify these disparities are emerging and should be enacted broadly throughout academia.

Women continue to be underrepresented in academic venues, particularly in leadership positions at universities, as speakers at national and international meetings, on foundation and review boards that distribute grant funding, and on editorial boards of journals (1). To shed more light on this issue, women on the JCI editorial board with support from our editor-in-chief, Rexford Ahima and the entire editorial board, got together to briefly outline the scope of the problem within this arena. Our objective was to track progress in this area, highlight strategies that have successfully increased female and minority representation within academic settings, and thereby illuminate approaches that will ultimately narrow this gap in academic medicine, including among top tier journals like the JCI.

The percentage of women medical students has been steadily increasing with slightly more $(52 \%)$ women enrolled in U.S. medical schools in 2018 (2). In fact, the 2019 medical student class at the Johns Hopkins University School of Medicine is predominantly female at $58 \%$. However, only $1 / 3$ of the current $\mathrm{MD} / \mathrm{PhD}$ students in the Medical Student Training Program are women. Similarly, the proportion of women faculty at U.S. medical schools is increasing, with an estimated 42\% in 2018 (3). Nonetheless, women remain underrepresented at the highest leadership positions. In 2006, women comprised $12 \%$ of medical school deans, $11 \%$ of department chairs, and $21 \%$ of division directors. By 2013 , women made up $16 \%$ of medical

\footnotetext{
Authorship note: MJK contributed to this article in her personal capacity. The views expressed are her own and do not necessarily represent the views of the National Institutes of Health or the United States Government. Conflict of interest: EMJ receives research funding from Bristol-Myers Squibb and Aduro Biotech, is on the advisory board for Cenocea Biosciences, and has the potential to receive royalties from Aduro Biotech. NSA receives research funding from Bristol-Myers Squibb, Merck, Celgene, Sydax, Astex, Intensity Therapeutics, Incyte, Debio, and Tanabe. $\mathrm{MH}$ is an advisor for Vicore and has received research funding from Roche. MJK receives research funding from MedImmune. ML receives research funding from Bluefield Innovations. MVM has received funding from Agenus, Crispr Therapeutics, Kite Pharma, and royalties from Novartis via the University of Pennsylvania. CJS has received funding from lonis Pharmaceuticals. MWK has received funding from Apellis Pharmaceuticals.

Copyright: ( 2019, American Society for Clinical Investigation.
}

Reference information: / Clin Invest. 2019;129(10):3974-3977. https://doi.org/10.1172/JCI130902. school deans in the United States, with only small increases in the percentage of department chairs and division directors, at $15 \%$ and $24 \%$, respectively (4).

To begin to define the scope of this problem at the Johns Hopkins University School of Medicine, the current home of the JCI editorial board, investigators (including one of the authors; LR) compared the number and percentage of women to men faculty holding leadership positions in 2012 within its largest department, the Department of Medicine (5). In keeping with national trends, but arguably even more pronounced, they found that $88 \%$ of the 16 division director positions were held by men. Notably, the Department of Medicine has never had a woman chair since the department was established in 1889. In contrast, this study found that secondary leadership positions, such as assistant or associate division directors, and education program directors, were held by women at levels proportionate to faculty representation (5). Given that these secondary positions were not leading to more prestigious leadership roles, at least in the short term, this led to the question of whether such roles could actually hamper career development and impede the ultimate attainment of the highest leadership roles. In 2019, the leadership landscape at Hopkins in the Department of Medicine remains similar, with $82 \%$ of 17 division director positions still held by men. Further, 18\% (three) division directors are underrepresented minorities, one of whom is a woman. These persistent disparities highlight the need for changes in current strategies to bridge gaps 
Women $\mathrm{ASCl}$ inductees and council members

$60 \%$

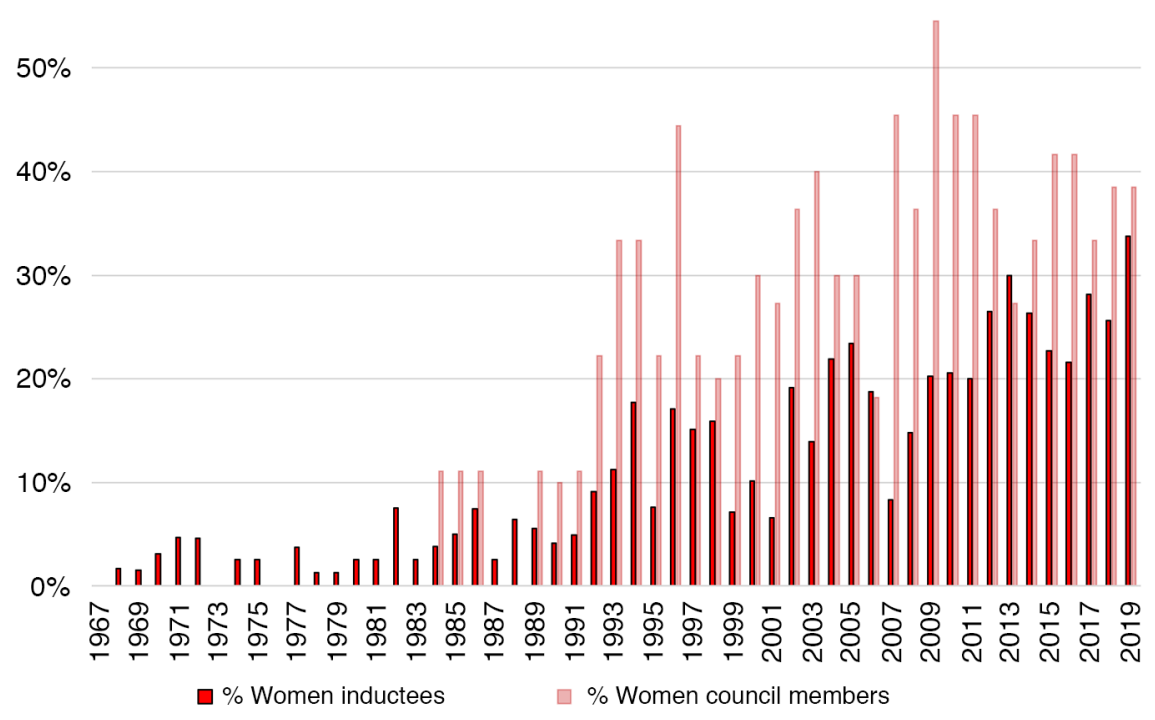

$\mathrm{JCl}$ associate editors by gender

35

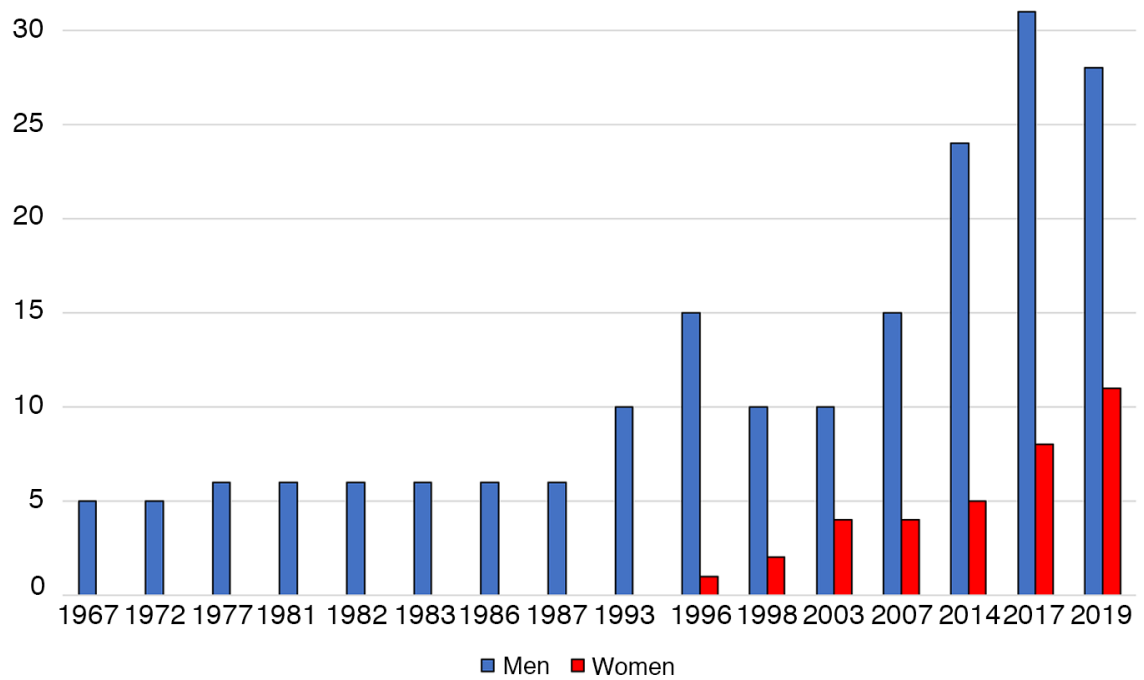

Figure 1. Women in the American Society for Clinical Investigation (ASCI) and the editorial board of the Journal of Clinical Investigation (JCI). (A) The percentage of new ASCl inductees that are women from 1967-2019 is shown in the red bars. ASCl council members select new ASCl inductees, and the percentage of women council members from is shown in pink bars. (B) The total number of $J C l$ associate editors is shown by gender and by year. Each year shown represents a different editor-in-chief's tenure, and the presented data are from one selected masthead in the indicated time period.

between men and women or other underrepresented groups in academia.

\section{The status of women at the American Society for Clinical Investigation (ASCI)}

Founded in 1908, the ASCI is an honorary society comprising over 3000 elected physician-scientists. The JCI has been its flagship journal since it began publication in 1924. The status of women at the ASCI has largely mirrored that of women in academic leadership. For example, it took over 30 years to elect the first woman, Dr. Marian Wilkes Ropes, to ASCI. Dr. Ropes was a pioneer in the pathogenesis of systemic lupus erythematosus; she graduated from Johns Hopkins Medical School and was the first woman admitted to the Massachusetts General Hospital residency program. Although the number of those elected annually increased over time, there were still only 1 or 2 women elected annually up to 1970 . In 1983, the ASCI council, which constitutes the governing body responsible for reviewing membership nominations, included its first woman, Dr. Suzanne Oparil. Dr. Oparil is a cardiologist and vascular biologist who currently leads the Vascular Biology and Hypertension Program at University of Alabama. Since 1990, the Council has been $20-45 \%$ female, and the percentage of women has concurrently expanded with $34 \%$ of ASCI inductees being women in 2019 (Figure 1A). These observations suggest that diversifying leadership structures can foster changes to professional societies and institutions by broadening the network and upholding role models.

\section{Women in leadership positions} in journals - the $\mathrm{JCl}$ experience

Today, the JCI has more women associate and consulting editors than ever before, indicating progress in this specific area (Figure 1B). However, and not surprisingly, women remain poorly represented on the journal's editorial board, underscoring the urgent need for further progress. Even more striking disparities exist for underrepresented minorities. The JCI editorial board also reflects disparities observed in leadership in academic medicine. While the structure of the JCI's editorial board has evolved over the course of the journal's 95-year history, the first woman to serve in any capacity did not appear until 1972 when Helen M. Ranney became a member of the external editorial committee. Dr. Ranney was a hematologist, Professor at Harvard Medical School, and the first woman to serve as president of the Association of American Physicians. She pioneered the use of paper electrophoresis to separate hemoglobin to diagnose sickle cell anemia (6). There were no women associate editors for the journal until 1995, when Carolyn J. Kelly joined the editorial board during the JCI's tenure at the University of California at San Diego. Dr. Kelly is a nephrologist, Professor of Nephrology, and Associate Dean whose work focuses on autoimmunity and kidney disease. 
Notably, the number of women represented on the editorial board has increased in the intervening years and is currently at an all-time high, with a total of $28 \%$ of associate editors (11/39). The journal has yet to have a woman deputy editor or editor-in-chief.

A commentary published in Nature in 2018 (7) highlighted similar disparities in other journals as reported in a study published in eLife, which found that editors are more likely to select reviewers of the same gender $(8,9)$. The impact of reviewer gender on publication success rates, however, was not assessed. In many scientific fields, women and other underrepresented groups publish less and are less likely to be listed as first or senior authors (9). In an effort to reduce sex-bias in author order on publications, the JCI recently enacted a policy requiring manuscript submissions to describe how the order of co-first authors was determined (10).

\section{Progress at the American Association of Cancer Research} - one society's experience

While pronounced disparities among women and underrepresented groups persist among leadership at most leading academic centers and editorial boards of high-tiered journals, notable progress was made at the American Association of Cancer Research (AACR), the largest cancer research organization in the world. Strikingly, this progress occurs in the backdrop of a gender gap in the oncology field (11) that includes disparities within leadership positions among national and international organizations and societies, representation on boards, as President of the organization, and as speakers at major meetings. A recent analysis looking at a one-year snapshot of female representation in major oncology societies documented this gap (11). Fortunately, some organizations, such as AACR, showed significant improvements in diversity at the top. For example, the AACR recently reported that women represent $40 \%$ of their membership and $45 \%$ of members of their Board of Directors (12), which was confirmed in this study (11). Further, 5 of the last 10 AACR Presidents have been women. These data suggest that diversity in leadership "trickles down" to diversity at all levels. In contrast, the American
Society of Clinical Oncology, the largest clinical oncology society in the world, has a lower rate of female representation on their board (25\%), although among the highest representation of women speakers at international congresses (34\%).

\section{How do we accelerate change?}

The progress in diversity, both among membership and in leadership at international organizations such as AACR, led us to ask, how did they do it? Dr. Elizabeth Jaffee, one of the authors and the 2018-2019 AACR President, notes that it is imperative for organizations to actively address gender and racial inequality in all levels of leadership. AACR has taken concrete measures to ensure equality throughout the organization in a number of ways. First, senior staff and society leaders within AACR and other successful organizations require a gender balance on nominating committees, program committees, and at research meetings and symposia. Thus, leaders in science need to take an active role in this process. For example, Francis Collins the NIH Director, recently pledged to decline to speak at conferences that do not included sufficient women in prominent speaking roles nor will he serve on all-male panels, dubbed "manels," a longstanding problem for women in STEM (13). Successful organizations must continue to encourage nominations of women for prizes and awards at their annual meetings, which will occur when the nominating committees are diverse. AACR has led in this arena, in part, by establishing groups within the organization that provide additional resources for developing leadership skills. For example, both the AACR Women in Cancer Research (WICR) and Minorities in Cancer Research (MICR) groups provide opportunities to support mentoring, leadership training, and networking relationships. Professional organizations should be encouraged to initiate and maintain such efforts while carefully monitoring progress as defined by diversity among leadership as a key parameter of success.

\section{Future directions - this is not rocket science!}

In addition to women, underrepresented groups continue to be "left out" of leadership positions in academic medicine. While there are an ever-expanding number of scholarly papers that document disparities of women and underrepresented minorities among leadership in academic settings, there is also a growing body of literature indicating that diversity among scientific teams leads to the most creative, insightful, and impactful science (14-17). Moreover, as outlined above for ASCI and AACR, requirements for balance in gender and underrepresented minorities on programmatic committees and leadership can help to foster diversity at all levels. Thus, the solutions seem relatively straight forward, yet have remained largely unattainable in academia. This is a call to action to all current and future leaders. We must proactively establish diversity in representation as a requirement for success in all aspects of academic leadership. Organizations should be encouraged - even required - to continue these efforts and monitor progress by representation of women and underrepresented minorities at all levels. Some funding agencies (the New York Stem Cell Foundation) are beginning to generate a "report card" for diversity within institutions seeking grant support and propose to use this information in funding decisions (18). It is clear that including more women and underrepresented minorities in positions of leadership at universities, journals, and scientific societies, will not only foster advances in human health and science for generations to come, but will also uphold values of inclusion and diversity.

\section{Acknowledgments}

We thank Rexford S. Ahima for helpful comments and support, and John B. Hawley for providing information on ASCI membership.

Address correspondence to: Linda M. S. Resar, Johns Hopkins University School of Medicine, 720 Rutland Avenue, Ross Research Building, Room 1025, Baltimore, Maryland 21205, USA. Phone: 410.614.0712; Email: lresar@jhmi.edu.

\footnotetext{
1. National Academies of Science, Engineering, Medicine, Policy Global Affairs, Committee on Women in Science, Engineering, Medicine, Committee on the Impacts of Sexual Harrassment in Academia. Johnson PA, Widnall SE, Benya FF, eds. Sexual Harassment of Women: Climate, Culture, and Consequences in Academic Sciences, Engineering, and Medicine. Washington, DC, USA: The National Academies Press; 2018.

2. Association of American Medical Colleges.
} 
AAMC Data. U.S. Medical School Faculty, 2018. Table A-7: Applicants, First-Time Applicants, Acceptees, and Matriculants to U.S. Medical Schools by Sex, 2009-2010 through 2018-2019. http://www.aamc.org/download/492954/data/ factstablea7_2.pdf. Accessed August 16, 2019.

3. Association of American Medical Colleges. AAMC Data. U.S. Medical School Faculty, 2018. Table 8: Medical School Faculty by Sex and Race/Ethnicity, 2018. http://www.aamc.org/download/495038/ data/18table8.pdf. Accessed August 16, 2019.

4. Association of American Medical Colleges. The State of Women in Academic Medicine, 20132014 Report. Washington, DC, USA: Association of American Medical Colleges Press; 2014.

5. Monroe AK, Levine RB, Clark JM, Bickel J, MacDonald SM, Resar LM. Through a Gender Lens: A View of Gender and Leadership Positions in a Department of Medicine.J Womens Health (Larchmt). 2015;24(10):837-842.

6. Bunn HF. Helen Margaret Ranney: A woman of many firsts. The Hematologist. 2008;5(2). http://www.hematology.org/thehematologist/ profiles/1302.aspx. Posted March 1, 2008. Accessed August 26, 2019.
7. Singh Chawla D. Huge peer-review study reveals lack of women and non-Westerners. Nature. 2018;561(7723):295-296.

8. Helmer M, Schottdorf M, Neef A, Battaglia D. Gender bias in scholarly peer review. Elife. 2017;6: e21718.

9. Murray D, et al. Author-Reviewer Homophily in Peer Review [preprint]. doi: https://doi. org/10.1101/400515. Posted on bioRxiv August 29, 2018.

10. Casadevall A, Semenza GL, Jackson S, Tomaselli G, Ahima RS. Reducing bias: accounting for the order of co-first authors. JClin Invest. 2019;129(6):2167-2168.

11. Banerjee S, et al. Gender-related challenges facing oncologists: the results of the ESMO Women for Oncology Committee survey. ESMO Open. 2018;3(6):e000422.

12. American Associate of Cancer Research. The AACR Drives Progress for Women in Oncology. Leading Discoveries. http://leadingdiscoveries. aacr.org/the-aacr-drives-progress-for-womenin-oncology. Accessed August 16, 2019.

13. Collins FS. National Institutes of Health Director Statements. Time to End the Manel
Tradition. http://www.nih.gov/about-nih/ who-we-are/nih-director/statements/timeend-manel-tradition. Posted June 12, 2019. Accessed August 26, 2019.

14. Gomez LE, Bernet P. Diversity improves performance and outcomes [published online ahead of print February 11, 2019]. J Natl Med Assoc. https://doi.org/10.1016/j.jnma.2019.01.006.

15. LaVeist TA, Pierre G. Integrating the 3Ds--social determinants, health disparities, and healthcare workforce diversity. Public Health Rep. 2014;129 Suppl 2:9-14.

16. Pitts DW. Diversity, representation, and performance: evidence about race and ethnicity in public organizations. Journal of Public Administration and Theory. 2005;15(4):615-631.

17. AlShebli BK, Rahwan T, Woon WL. The preeminence of ethnic diversity in scientific collaboration. Nat Commun. 2018;9(1):5163.

18. New York Stem Cell Foundation (NYSCF) Initiative on Women in Sscience and Engineering (IWISE) Working Group. The Report Card for Gender Equality. http://nyscf.org/programs/community-building/women-in-science/the-report-cardfor-gender-equality. Accessed August 6, 2019. 